\title{
BIODIVERSIDADE: O NOVO MARCO REGULATÓRIO DO ACESSO AO CONHECIMENTO TRADICIONAL ASSOCIADO E A REPARTIÇÃO DE BENEFÍCIOS DECORRENTES DE SUA EXPLORAÇÃO ECONÔMICA
}

\author{
Lyssandro Norton Siqueira $^{1}$ \\ Grace Ladeira Garbaccio ${ }^{2}$ \\ Carlos Alberto Rohrmann ${ }^{3}$
}

\section{RESUMO}

No âmbito da Convenção sobre Diversidade Biológica (CDB) foi iniciada a negociação de um regime internacional sobre acesso ao conhecimento tradicional associado à biodiversidade. No Brasil, a ausência de instrumentos jurídicos adequados permitia a ocorrência de grandes controvérsias acerca do tema. Este estudo examina o novo marco legislativo brasileiro, na regulação jurídica do acesso ao conhecimento tradicional associado à biodiversidade e repartição de benefícios. Metodologia utilizada: jurídico-teórica e procedimento de raciocínio dedutivo. Técnica de pesquisa doutrinária.

Palavras-chave: Biodiversidade; conhecimento tradicional; meio ambiente; população tradicional; propriedade intelectual.

\section{BIODIVERSITY: THE NEW REGULATORY FRAMEWORK FOR ACCESS TO TRADITIONAL ASSOCIATED KNOWLEDGE AND THE BREAKDOWN OF BENEFITS ARISING OUT OF ITS ECONOMIC EXPLORATION}

\footnotetext{
${ }^{1}$ Doutor em Teoria do Estado e Direito Constitucional pela PUC/RIO. Mestre em Direito Empresarial pela Faculdade de Direito Milton Campos (2007). Graduado em Direito pela Universidade Federal de Minas Gerais (1995). Procurador do Estado de Minas Gerais e Coordenador de Área de Meio Ambiente (Advocacia-Geral do Estado). Professor do Centro Universitário UNA e do Centro Universitário UNI-BH. Professor dos Cursos de Especialização em Direito Ambiental do Centro Universitário UNA e da Faculdade Milton Campos. Professor do Centro de Direito Internacional (CEDIN). Coordenador, em Minas Gerais, da Associação dos Professores de Direito Ambiental do Brasil (APRODAB). Coordenador na Região Sudeste do Instituto Brasileiro de Advocacia Pública (IBAP). Possui artigos e livros publicados no Brasil e no exterior. Instituição: Centro Universitário Unibh, Minas Gerais Escola Superior Dom Hélder Câmara. Brasil. E-mail: lyssandro.norton@gmail.com

2 Profissional da área de Sustentabilidade/Gestão Ambiental, Jurídica, Governança, Compliance, Comunicação e RH, formada em Direito pela Universidade Federal de Minas Gerais (2002) e em Administração pela Fundação João Pinheiro (2000), com Mestrado em Direito Ambiental pela Université de Limoges (2005) e Doutorado em Direito Ambiental - Université de Limoges (2009). Experiência nas áreas de Direito, Meio Ambiente, Responsabilidade Social, Segurança do Trabalho, Comunicação e Marketing em empresas como Vallourec, Saint Gobain, Anglo American e Votorantim Energia, bem como no poder executivo do Estado de MG em suas Secretarias. Francês Fluente, Inglês Avançado, Italiano e Espanhol Intermediário.Professora do Programa Stricto Sensu do Mestrado em Direito do Instituto IDP. Instituição: Professora do Programa Stricto Sensu do Mestrado em Direito do Instituto IDP. Brasil. E-mail: glgarbaccio@hotmail.com

${ }^{3}$ Doutor em Direito (Doctor of the Science of Law) pela University of California, Berkeley (2001), possui também mestrado em Direito (Master of Laws - LL.M.) pela University of California at Los Angeles - UCLA (1999), ambos revalidados pela UFMG, mestrado em Direito Comercial pela Universidade Federal de Minas Gerais (1999), graduação em Direito pela Faculdade de Direito Milton Campos (1996) e graduação em Ciência da Computação pela Universidade Federal de Minas Gerais (1994). Instituição: Faculdades Milton Campos, Minas Gerais. Brasil. Email: rohrmann@bis.com.br
} 


\section{ABSTRACT}

Under the Convention on Biological Diversity (CBD), an international regime on access to traditional knowledge associated with biodiversity has been negotiated. In Brazil, the absence of adequate legal instruments allowed the occurrence of great controversies on the subject. This study examines the new Brazilian legislative framework in the legal regulation of access to traditional knowledge associated with biodiversity and benefit sharing. Methodology used: juridical-theoretical and procedure of deductive reasoning. Doctrinal research technique.

Keywords: Biodiversity; environment; intellectual property; traditional knowledge; traditional population.

\section{INTRODUÇÃO}

A Convenção de Diversidade Biológica (CDB), resultado da Conferência das Nações Unidas para o Meio Ambiente e o Desenvolvimento (CNUMAD), realizada no Rio de Janeiro, em junho de 1992, constitui um dos instrumentos internacionais mais importantes relacionados ao meio ambiente. Promulgada no Brasil, pelo Decreto n. 2519/1998, a CDB tem por objetivo a conservação da diversidade biológica, a utilização sustentável de seus componentes e a repartição justa e equitativa dos benefícios derivados da utilização do patrimônio genético.

O Brasil, o país mais rico do mundo em biodiversidade, abrigando mais de 20\% (vinte por cento) do total de espécies da Terra ${ }^{4}$, tem importante papel no cenário mundial. No entanto, a ausência de instrumentos jurídicos adequados para sua proteção gerava grandes controvérsias acerca do tema, com suspeitas de apropriação indevida da biodiversidade brasileira e do conhecimento tradicional a ela associado, para produzir os mais variados itens comerciais, com registro de patentes e exploração de marcas, sem considerar a titularidade deste conhecimento, pelas populações tradicionais.

A primeira normatização da questão ocorreu com a edição da MP n. 2.186-16/2001, regulamentando o inciso II do $\S 1$ o e o $\S 4$ o do art. 225 da Constituição Federal e dispondo sobre o acesso ao patrimônio genético, sobre a proteção e o acesso ao conhecimento tradicional associado e sobre a repartição de benefícios para conservação e uso sustentável da biodiversidade. A MP n. 2.18616/2001 teve o mérito de regulamentar o tema, mas seu conteúdo gerou diversas controvérsias e

\footnotetext{
${ }^{4}$ BRASIL. Ministério do Meio Ambiente. Disponível em <http://www.mma.gov.br/biodiversidade/biodiversidadebrasileira>. Acesso em 23.out.2018.
} 
discussões conceituais que acabaram dificultando a garantia dos direitos dos detentores de conhecimentos tradicionais associados que são usados pelas comunidades científicas e pelos empreendedores do setor (MACHADO; GODINHO, 2018, p. 99).

Com a publicação da Lei n. 13.123/2015 e do Decreto n. 8.772/2016, criou-se a expectativa de efetividade da regulação da proteção da biodiversidade e dos conhecimentos tradicionais a ela associados.

Tendo como marco teórico legislativo a Lei n. 13.123/2015, o objetivo específico do trabalho é a análise da nova regulamentação jurídica da obrigação de repartição de benefícios decorrentes do acesso ao conhecimento tradicional associado à biodiversidade.

Este trabalho foi desenvolvido com a metodologia jurídico-teórica e procedimento de raciocínio dedutivo, utilizando-se de técnica de pesquisa doutrinária para atingir seus objetivos.

\section{CONHECIMENTO TRADICIONAL ASSOCIADO À BIODIVERSIDADE: CONCEITOS E NORMAS DE PROTEÇÃO}

\subsection{Conceitos legais}

Biodiversidade, segundo a CDB, é "o conjunto de organismos vivos de todas as origens, compreendendo, entre outros, os ecossistemas terrestres, marinhos e outros ecossistemas aquáticos e os complexos ecológicos de que fazem parte" ${ }^{5}$ Ao conjunto de informações de origem genética da biodiversidade, incluindo substâncias oriundas do metabolismo destes seres vivos, dá-se o nome patrimônio genético, no termos do art. 2º I, da Lei n. 13.123/2015.

Para a Organização Mundial de Propriedade Intelectual, o Conhecimento Tradicional é definido como "tradição literária, artística ou científica, performances, invenções, descobertas científicas, desenhos, marcas, nomes e símbolos e outras inovações e criações resultantes da atividade intelectual nos campos da indústria, ciência e das artes" (MENDONÇA, 2006, p. 551). Os conhecimentos tradicionais podem estar ou não associados à biodiversidade. Na lição de Guilherme Cruz de Mendonça (MENDONÇA, 2006, p. 551), conhecimentos tradicionais são aqueles desenvolvidos e acumulados por populações tradicionais, passados oralmente de geração em geração.

Mostra-se necessária, para complementação da definição, a delimitação do conceito de população tradicional. Populações tradicionais são grupos de pessoas, indígenas ou não, com organização social e atividades culturais próprias, transmitidas historicamente através de sucessivas gerações, e que utilizam de forma sustentável os recursos naturais, dos quais dependem para sua subsistência.

\footnotetext{
5 BRASIL. Ministério do Meio Ambiente. Convenção de Diversidade Biológica. Disponível em < http://www.mma.gov.br/informma/item/7513-conven\%C3\%A7\%C3\%A3o-sobre-diversidade-biol\%C3\%B3gicacdb>. Acesso em 24.out.2018.
} 
A Lei n. 11.428, de 22 de dezembro de 2006 - que dispõe sobre a utilização e proteção da vegetação nativa do Bioma Mata Atlântica -, definiu, em seu artigo 3o, que "população tradicional é aquela que vive em estreita relação com o ambiente natural, dependendo de seus recursos naturais para a sua reprodução sociocultural, por meio de atividades de baixo impacto ambiental."

Regulamentando a Lei n. 11.428/2006, o Decreto n. 6.040, de 7 de fevereiro de 2007, que institui a Política Nacional de Desenvolvimento Sustentável dos Povos e Comunidades Tradicionais. Limitou o conceito legal, definindo povos e comunidades tradicionais como grupos culturalmente diferenciados e que se reconhecem como tais, que possuem formas próprias de organização social, que ocupam e usam territórios e recursos naturais como condição para sua reprodução cultural, social, religiosa, ancestral e econômica, utilizando conhecimentos, inovações e práticas gerados e transmitidos pela tradição. Este conceito de comunidade tradicional foi consolidado pelo art. 2o, IV, da Lei n. $13.123 / 2015$.

Assim, conciliando os conceitos isolados, o art. 20, II, da Lei n. 13.123/2015, estabeleceu que conhecimento tradicional associado é a informação ou prática de população indígena, comunidade tradicional ou agricultor tradicional sobre as propriedades ou usos diretos ou indiretos associada ao patrimônio genético.

Reunindo, portanto, os elementos dos diversos conceitos legais pode-se definir conhecimento tradicional associado ao patrimônio genético como aquele, adquirido e transmitido de geração a geração por populações tradicionais, relacionado ao seu modo de vida, incluindo "técnicas de manejo de recursos naturais, métodos de caça e pesca, conhecimento sobre os diversos ecossistemas e sobre propriedades farmacêuticas, alimentícias e agrícolas de espécies e as próprias categorizações e classificações de espécies de flora e fauna utilizadas pelas populações tradicionais" (SANTILLI, 2005, p. 192).

\subsection{Evolução do sistema normativo protetivo: breve histórico}

Quanto à biodiversidade e ao conhecimento tradicional a ela associado, pode-se afirmar que a CDB é o instrumento jurídico protetivo de maior abrangência internacional. A proteção aos conhecimentos tradicionais é tratada pela CDB em seu artigo 8o, "j", que dispõe que deverão ser respeitados, preservados e mantidos o conhecimento, as inovações e práticas das comunidades locais e populações indígenas com estilos de vida tradicionais relevantes à conservação e utilização sustentável da diversidade biológica (FILIPPIN, 2014, p. 147).

A normatização explícita do tema no Brasil tem origem na própria Constituição da República de 1988 que, em seu artigo 225, $\S 1$ o, II, buscando assegurar o direito de todos ao meio ambiente 
ecologicamente equilibrado, impõe ao Poder Público preservar a diversidade e a integridade do patrimônio genético do País e fiscalizar as entidades dedicadas a sua pesquisa e manipulação.

Em 29 de junho de 2000, foi editada a Medida Provisória n. 2.052, reeditada, em 23/08/2001, pela Medida Provisória n. $2.186^{6}$, que regulamentava o inciso II do $\S 1$ e e o $\S 4$ o do art. 225 da Constituição, os arts. 1ํ, 8o, alínea "j", 10, alínea "c", 15 e 16, alíneas 3 e 4 da Convenção sobre Diversidade Biológica, dispondo sobre o acesso ao patrimônio genético, a proteção e o acesso ao conhecimento tradicional associado, a repartição de benefícios e o acesso à tecnologia e transferência de tecnologia para sua conservação e utilização. Com a MP foi criado o Conselho de Gestão do Patrimônio Genético - $\mathrm{CGEN}^{7}$, com caráter deliberativo e normativo, responsável pela tomada de decisões em relação ao acesso ao conhecimento tradicional associado ao patrimônio genético.

As sanções aplicáveis às condutas e atividades lesivas ao patrimônio genético ou ao conhecimento tradicional associado somente foram previstas, quatro anos mais tarde, pelo Decreto $\mathrm{n}$. 5.479, de 7 de junho de 2005, que regulamentou o artigo 30 da Medida Provisória n. 2.186-16, de 23 de agosto de 2001.

Ainda regulamentando o acesso ao patrimônio genético, entraram em vigor, em 2007, a Resolução n. 134/2006 ${ }^{8}$, do Instituto Nacional de Propriedade Intelectual (INPI), e a Resolução n. 23/2006 ${ }^{9}$, do Conselho de Gestão do Patrimônio Genético (CGEN). Posteriormente, o CGEN, através da Resolução no 34, de 12 de fevereiro de 2009, estabeleceu a forma de comprovação da observância da Medida Provisória no 2.186-16, de 23 de agosto de 2001, para fins de concessão de patentes de invenção pelo Instituto Nacional da Propriedade Industrial - INPI, exigindo que fosse informada a origem do material genético e do conhecimento tradicional associado, bem como o número da correspondente autorização de acesso.

\footnotetext{
${ }^{6}$ A MP n. 2.186/2000 se manteve em vigor, por força da Emenda Constitucional n. 32, de 11 de setembro de 2001. ${ }^{7}$ O Decreto n. 3.945, de 28 de setembro de 2001, definiu a composição do e estabelecendo as normas para o seu funcionamento, mediante a regulamentação dos artigos. 10,11, 12, 14, 15, 16, 18 e 19 da Medida Provisória n. 2.186-16

${ }^{8}$ A resolução do INPI, complementando a resolução do CGEN, dispôs que o requerente de pedido de patente depositado a partir da data de vigência daquela outra resolução deverá declarar se o objeto do pedido de patente foi obtido, ou não, em decorrência de um acesso à amostra de componente do patrimônio genético nacional, realizado a partir de 30 de junho de 2000. O INPI exigia, ainda, que, na hipótese de o objeto do pedido de patente ter sido obtido em decorrência de um acesso a amostra de componente do patrimônio genético nacional, o requerente deverá declarar, também, que foram cumpridas as determinações da Medida Provisória n. 2.186-16, de 2001, informando o número e a data da autorização do acesso correspondente, bem como a origem do material genético e do conhecimento tradicional associado, quando for o caso.

${ }^{9}$ A Resolução do CGEN dispôs, em seu artigo 2으, que, para fins de comprovação do atendimento ao disposto na Medida Provisória n. 2.186-16, de 2001, o requerente do pedido de patente de invenção de produto ou processo resultante de acesso a componente do patrimônio genético realizado desde 30 de junho de 2000, depositado a partir da data de publicação daquela resolução, deverá declarar ao INPI que cumpriu as determinações da medida provisória, bem como informar o número e a data da autorização de acesso correspondente, sob pena de sujeição às sanções cabíveis.
} 
Mais recentemente, a edição da Lei n. 13.123/2015 e do Decreto n. 8.772/2016 deu nova contribuição para a regulamentação do tema, o que será tratado a seguir.

\section{CDB X TRIPS: A PROTEÇÃO DO CONHECIMENTO TRADICIONAL ASSOCIADO À BIODIVERSIDADE E A REPARTIÇÃO DE BENEFÍCIOS}

A proteção do conhecimento tradicional associado à biodiversidade não pode ser dissociada da necessidade de aproveitamento econômico desse conhecimento, dentro de um ambiente de desenvolvimento sustentável.

A diversidade biológica fornece produtos para exploração e consumo, sendo importante a sua valorização, pois a redução da biodiversidade e a prática de procedimentos que impliquem em biopirataria comprometem a sustentabilidade do meio ambiente e a disponibilidade permanente dos recursos naturais. Por outro lado, não se deve negar o acesso ao conhecimento tradicional associado à biodiversidade em razão da importância para o desenvolvimento econômico dos países de origem (DAVIES, 2015, p. 76).

A questão controvertida diz respeito à utilização indiscriminada por empreendedores dos conhecimentos tradicionais associados à biodiversidade, sem qualquer autorização ao acesso nem repartição dos benefícios dele decorrentes com as populações tradicionais.

Os empreendedores, para justificar a recusa à repartição dos benefícios decorrentes do acesso ao conhecimento tradicional, invocam em defesa de seus procedimentos o atual sistema de proteção à propriedade intelectual, especialmente o relativo a marcas e patentes. Esse sistema de proteção tem seu marco normativo internacional com a inclusão do "Acordo sobre Aspectos de Direitos da Propriedade Intelectual relacionados ao Comércio" (TRIPS - Trade Related Aspects of Intellectual Property Rights), no "Acordo Constitutivo da Organização Mundial do Comércio - OMC, com seu Anexo 1C, tendo entrado em vigor em 1 o de janeiro de 1995. O TRIPs é considerado um acordo internacional de padrões mínimos de proteção, assegurando, entre os seus princípios básicos de não discriminação, os de que nenhum membro do TRIPs pode tratar diferentemente os demais membros, nem estabelecer desigualdade entre nacionais e estrangeiros (BARBOSA, 2005, p. 52).

A aplicação das regras do TRIPs, em algumas situações, pode ser viável para a regulação do acesso aos conhecimentos tradicionais associados à biodiversidade, desde que respeitados os princípios consagrados em seu artigo 8으, que incentivam a adoção de medidas aptas a evitar o abuso dos direitos de propriedade intelectual ou o recurso a práticas que limitem de maneira injustificável o comércio. No mesmo sentido, mostra-se útil a flexibilidade conferida aos países membros pelo disposto no artigo 30 que Ihes permite conceder exceções limitadas aos direitos exclusivos conferidos pela patente. 
Por outro lado, como o TRIPs trata de direito de propriedade intelectual, de interesse essencialmente privado, há sérias incompatibilidades para o trato dos conhecimentos coletivos das comunidades tradicionais. Assim, sob esta proteção, algumas empresas já registraram, como marca, substâncias naturais originárias dos países megadiversos (além do Brasil, atual presidente do grupo, fazem parte do grupo de países megadiversos a África do Sul, Bolívia, China, Colômbia, Congo, Costa Rica, Equador, Filipinas, Índia, Indonésia, Madagascar, Malásia, México, Peru, Quênia e Venezuela). ${ }^{10}$

Diversos são os exemplos de utilização indevida de substâncias naturais e conhecimentos tradicionais a elas associados, como o relativo à empresa alemã Rapunzel Naturkost que, no passado, registrou a propriedade intelectual da rapadura. Em 2008, o governo brasileiro apresentou uma proposta à empresa de registro de marca composta. Acolhendo a proposta, a empresa informou que faria o seu registro composto - Rapadura Rapunzel —, sem que haja qualquer direito de exclusividade sobre o termo rapadura. ${ }^{11}$

Essas empresas, contudo, que têm utilizado os produtos naturais indevidamente não respeitam nem mesmo o TRIPs, que, em seu artigo 27.3(b), autoriza que seus membros recusem as patentes de plantas e animais.

No bojo da controvérsia sobre a possibilidade ou impossibilidade de patenteamento de produtos naturais, há que se destacar que, no Brasil, teve solução amigável um caso que caminhava para ser o primeiro precedente jurisprudencial sobre conhecimento tradicional associado à biodiversidade. Feirantes do Mercado Ver-o-Peso, de Belém/PA, acusaram a empresa de cosméticos Natura de se apropriar indevidamente de seu conhecimento tradicional. A polêmica teve início há alguns anos, quando pesquisadores da Natura visitaram o mercado de Belém e gravaram depoimentos com vendedoras de ervas, pagando-lhes $R \$ 500,00$ (quinhentos reais) pela cessão dos direitos de imagem.

Algum tempo depois, a Natura lançou o perfume e a água de banho de breu branco, uma das ervas vendidas na feira, com base supostamente no conhecimento obtido com as feirantes. Alertadas por representantes da OAB de Belém quanto aos seus possíveis direitos, as feirantes passaram ao conflito com a empresa.

Após alguns embates administrativos (não houve o ajuizamento de ação), a Natura reconheceu que os produtos em questão teriam como origem o conhecimento tradicional, aceitando repartir com as feirantes os benefícios do uso de seus conhecimentos com o breu branco, a priprioca e o cumaru. $O$ acordo foi feito em reunião com participação de representantes do grupo de ervas do Ver-o-Peso,

\footnotetext{
${ }^{10}$ BRASIL. Ministério do Meio Ambiente. Disponível em <http://www.mma.gov.br/informma/item/6141-paisesmegadiversos-discutem-reparticao-de-beneficios>. Acesso em 24.out.2018.

11 Conjur, 23.jul.2008. Disponível em: <http://www.conjur.com.br/2008-jul23/empresa_alema_desiste_registro_marca_rapadura>. Acesso em: 9 ago. 2017.
} 
Ministério Público do Estado do Pará, Ministério Público Federal e 4ạ Câmara do Ministério Público Federal, empresa Natura e a Ordem dos Advogados do Brasil (OAB), Seção Pará, representada pela então presidente da Comissão de Bioética e Proteção do Biodireito, Eliane Moreira. ${ }^{12}$

A solução consensual do caso apontado acabou por encobrir a fragilidade do sistema normativo de então que não regulava de forma clara o acesso ao conhecimento tradicional associado à biodiversidade, provocando a insegurança jurídica das partes envolvidas.

Os casos narrados estariam em flagrante ofensa à CDB, em especial ao disposto no seu artigo 8o, "j", que determina a cada país signatário, em conformidade com sua legislação nacional, respeitar, preservar e manter o conhecimento, inovações e práticas das comunidades locais e populações indígenas com estilo de vida tradicionais relevantes à conservação e à utilização sustentável da diversidade biológica e incentivar sua mais ampla aplicação com a aprovação e a participação dos detentores desse conhecimento, inovações e práticas; e encorajar a repartição equitativa dos benefícios oriundos da utilização desse conhecimento, inovações e práticas.

Nesse sentido, mostra-se necessária a evolução de um sistema de normas internacionais que concilie os dispositivos da CDB com os do TRIPs.

\section{NECESSIDADE DE EVOLUÇÃO DO SISTEMA NORMATIVO DE REGULAÇÃO DO ACESSO AO CONHECIMENTO TRADICIONAL ASSOCIADO}

A solução para o problema da falta de proteção ao conhecimento tradicional associado à biodiversidade passa pela normatização de regras, já consagradas na CDB, que exijam, para o reconhecimento de patentes, a identificação da fonte do conhecimento tradicional utilizado, a prova da obtenção do consentimento prévio e a repartição justa dos benefícios obtidos.

Esse novo sistema normativo compatibilizaria a CDB com o TRIPS, devendo respeitar três princípios básicos: consentimento prévio informado, termos mutuamente acordados e compartilhamento dos benefícios (FINGER, 2007, p. 15).

Para Juliana Santilli (SANTILLI, 2004, p. 357), alguns elementos fundamentais devem nortear a construção de um sistema por ela denominado de sui generis: o pluralismo jurídico, através do reconhecimento e fortalecimento das normas internas e do direito costumeiro, não-oficial, dos povos indígenas, quilombolas e populações tradicionais; o respeito aos sistemas próprios de representação; o livre intercâmbio e troca de informações entre as próprias comunidades tradicionais; a distinção entre direitos intelectuais coletivos de conteúdo moral e patrimonial e o respeito à autonomia de vontade dos povos tradicionais e a requisitos essenciais de validade de atos jurídicos. A consulta prévia às

\footnotetext{
12 PARÁ: OAB/PA. Disponível em: <http://www.oab.pa.org.br>. Acesso em: 10 abr. 2007.
} 
comunidades tradicionais teria o objetivo de informá-las sobre a utilização do conhecimento tradicional associado e, com isso, permitir que, por acordo mútuo, participem da estipulação dos benefícios a ser partilhados depois da exploração (VISENTIN, 2012, p. 176).

Em que pese o anseio dos países-membros da CDB em criar um regime jurídico sui generis, que seria adequado aos conflitos específicos relacionados ao tema, tal iniciativa seria de difícil implementação em face da prévia e sólida existência do regime geral da propriedade intelectual, que tem como defensores fortes organizações como a OMPI, a OMC e a OECD.

Além disso, a consolidação de um novo e específico sistema jurídico destinado à perfeita regulamentação do acesso ao conhecimento tradicional associado à biodiversidade teria vários desafios a serem enfrentados.

Um deles seria a identificação prévia destes "conhecimentos" e das respectivas "comunidades". A informalidade que cerca o desenvolvimento e uso dos "conhecimentos tradicionais" impede uma perfeita identificação de sua origem, efeitos práticos, benefícios gerados e, notadamente, a titularidade das comunidades responsáveis. Com efeito, não se mostra tarefa fácil identificar previamente qual, ou quais, comunidades seriam responsáveis por determinado conhecimento, embora haja a possibilidade de, posteriormente, fazer uma investigação criteriosa e detalhada.

Para minorar o problema de segurança na identificação dos conhecimentos tradicionais, alguns países, como a Índia, têm buscado adotar como solução a formação de banco de dados de conhecimento tradicional.

Tal iniciativa, no sentido de identificar e catalogar os conhecimentos tradicionais, especialmente no Brasil, já teve sua importância ressaltada, no início do século XIX, pelo cientista francês Auguste de Sain-Hilaire (SAINT-HILAIRE, 1974, p. 49):

Seja como for, sente-se que a matéria médica dos brasileiros, baseada somente no empirismo deve ser muito imperfeita. Todavia, entre tantas plantas às quais falsamente se atribuem propriedades maravilhosas, algumas existem que realmente fornecem remédios eficacíssimos. Se existisse no Brasil maior número de homens instruídos, o governo desse país faria obra de grande utilidade, nomeando em cada província uma comissão que se encarregasse de submeter, a exame minucioso, todas as plantas de que se utilizam os colonos para aliviar seus males. Por esse meio, poder-se-ia chegar a constituir, para os vegetais, uma matéria médica brasileira, que elucidaria os colonos a respeito de remédios ineficazes ou perigosos e, ao mesmo tempo, daria a conhecer aos nacionais e aos estrangeiros grande número de plantas benéficas. Trabalho de tal envergadura não se poderá fazer, sem dúvida, senão daqui a longos anos.

Ultrapassado este primeiro difícil passo, há que se precisar a composição de tal comunidade, sua extensão e, principalmente, sua representatividade. Cumpre lembrar que, nos países ricos em biodiversidade, boa parte dos conhecimentos tradicionais foram desenvolvidos por indígenas, que são historicamente tratados como hipossuficientes. 
As dificuldades na identificação dos titulares dos conhecimentos tradicionais implicam insegurança jurídica tanto para as próprias comunidades como para quem pretende ter acesso ou explorar economicamente determinado conhecimento.

A implementação das exigências de identificação da origem do conhecimento tradicional, objeto do possível pedido de registro de patente, pode gerar confrontos com as normas do TRIPs. Segundo Graham Dutfield (DUTFIELD, 2004, p. 93), não haveria violação do TRIPs se as exigências ficassem restritas à descrição do conhecimento tradicional e à concordância expressa com as normas de acesso e repartição de benefícios. O mesmo autor alerta, contudo, que a exigência de revelação da origem geográfica do material genético e do conhecimento tradicional associado acarretaria uma revisão do TRIPs, que para o patenteamento exige que a invenção seja nova, envolva um passo inventivo e seja passível de aplicação industrial (artigo 27, 1). Tal conflito poderia ser, em tese, contornado, se essas exigências fossem feitas fora dos processos como medidas administrativas.

Uma solução procedimental é sugerida por Juliana Santilli, que relaciona, como uma das premissas para um regime legal sui generis, a "previsão da inversão do ônus da prova em favor das comunidades tradicionais em ações judiciais que visem anular patentes concedidas a processos ou produtos resultantes de seus conhecimentos, de forma que competiria à pessoa ou empresa demandada provar o contrário" (SANTILLI, 2003, p. 89). A solução apontada é de discutível efetividade, pois, além de parcial, somente se aplicaria se unida a outros instrumentos legais, definidores de legitimidade e representatividade das comunidades tradicionais, deixando de trazer segurança jurídica ao tema.

Merece destaque a solução encontrada no famoso caso do "nim", uma árvore da Índia utilizada com fins farmacológicos, conforme bem destacado por Juliana Santilli (SANTILLI, 2004, p. 348):

Alguns casos de biopirataria ganharam repercussão internacional, como o do nim (em inglês, neem), árvore da Índia, usada há séculos nesse país como fonte de biopesticidas e remédios. A empresa multinacional norte-americana W.R. Grace Corporation e o Departamento de Agricultura dos EUA conseguiram obter, junto ao Escritório Europeu de Patentes, seis patentes sobre produtos e processos derivados do nim indiano. Entre elas, uma patente sobre um método de preparação de um óleo com propriedades pesticidas, extraído das sementes da árvore. A revogação de tal patente foi requerida por um grupo de pessoas e organizações: Vandana Shiva, diretora da Research Foundation for Science, Technology and Ecology; Linda Bullard, presidente da International Federation of Organic Agricultural Moviments e Magda Alvoet, ministra belga da Saúde e do Ambiente. Ao final de cinco anos de batalha legal, no dia 10/05/2000, o Escritório Europeu de Patentes revogou a patente com base no argumento de que o processo patenteado pelos norte-americanos não atendia ao requisito da novidade. A decisão de revogar a patente se fundamentou no depoimento de um dono de uma fábrica indiana, nos arredores de Nova Déli que demonstrou utilizar processo semelhante ao patenteado pelos norte-americanos desde 1995, e não no desrespeito frontal aos princípios da Convenção sobre a Diversidade Biológica. 
Uma alternativa que se mostra razoável, até que se obtenha a desejada normatização internacional, é aquela defendida por Megan Bowman (BOWMAN, 2006), no sentido de que a conciliação entre a CDB e o TRIPs se dê através da aplicação flexível de dispositivos do TRIPs.

O artigo 70 do TRIPs prevê que a proteção e a aplicação de normas de proteção dos direitos de propriedade intelectual devem contribuir para a transferência e difusão de tecnologia de uma forma conducente ao bem-estar social e econômico e a um equilíbrio entre direitos e obrigações. Tal dispositivo permitiria a implementação de mecanismos aptos a regularem a repartição dos benefícios da tecnologia obtida com o acesso ao conhecimento tradicional associado, como forma de conduzir ao bem-estar social e a um equilíbrio de direitos e obrigações.

Já a proteção contra o acesso não autorizado aos conhecimentos tradicionais poderia ser assegurada pelo disposto no artigo 8o, "2", que prevê a imposição de medidas apropriadas para evitar o abuso dos direitos de propriedade intelectual por seus titulares ou para evitar o recurso a práticas que limitem de maneira injustificável o comércio ou que afetem adversamente a transferência internacional de tecnologia.

Outro ponto de conciliação poderia surgir a partir do que dispõe o artigo 27, que, após elencar os requisitos para a concessão de patentes, faculta aos signatários considerar como não patenteáveis invenções cuja exploração em seu território seja necessário evitar para proteger a ordem pública ou a moralidade, a vida ou a saúde humana, animal ou vegetal ou para evitar sérios prejuízos ao meio ambiente, desde que esta determinação não seja feita apenas porque a exploração é proibida por sua legislação.

O dispositivo acrescenta, ainda, que poderão ser considerados não patenteáveis as plantas e os animais, exceto microrganismos e processos essencialmente biológicos para a produção de plantas ou animais, excetuando-se os processos não biológicos e microbiológicos. Não obstante, os membros concederão proteção a variedades vegetais, seja por meio de patentes, seja por meio de um sistema "sui generis" eficaz, seja por uma combinação de ambos.

O artigo 30 dispõe que os membros poderão conceder exceções limitadas aos direitos exclusivos conferidos pela patente, desde que elas não conflitem de forma não razoável com sua exploração normal e não prejudiquem de forma não razoável os interesses legítimos de seu titular, levando em conta os interesses legítimos de terceiros.

Já o artigo 67 dispõe que os países-membros desenvolvidos, a pedido, e em termos e condições mutuamente acordadas, prestarão cooperação técnica e financeira aos países-membros em desenvolvimento. Essa cooperação incluirá assistência na elaboração de leis e regulamentos sobre proteção e aplicação de normas de proteção dos direitos de propriedade intelectual, bem como sobre 
a prevenção de seu abuso, e incluirá apoio ao estabelecimento e fortalecimento dos escritórios e agências nacionais competentes nesses assuntos, e na formação de pessoal, inclusive.

Ressalte-se, todavia, que, em que pese o disposto no artigo 30 do TRIPs poder viabilizar, em tese, a aplicação restritiva de patentes, a solução não se mostraria simples.

O dispositivo em comento não possui força coercitiva sobre os Estados signatários, ou seja, se os países considerados desenvolvidos reconhecerem em suas respectivas legislações patentárias a patente dos produtos obtidos por suas empresas por meio do conhecimento tradicional, não haverá qualquer restrição internacional a tanto.

Além disso, a redação do artigo 30 está carregada de expressões altamente subjetivas, como "não razoável" ou "exploração normal" que podem resultar na sua total inaplicabilidade.

A ausência dessa regulação geral e a utilização precária do sistema de patentes fomenta a insegurança jurídica em torno da questão, propiciando, de forma recorrente, a alegação de ausência de novidade.

As normas existentes deixam em aberto o grande problema da efetiva identificação dos conhecimentos tradicionais, dos seus titulares e dos beneficiários da eventual repartição de benefícios.

Neste sentido, a edição da Lei n. 13.123/2015, regulamentada pelo Decreto n. 8.772/2016, revela-se como boa contribuição para uma maior segurança jurídica na solução das controvérsias jurídicas sobre o tema no Brasil.

\section{O NOVO MARCO REGULATÓRIO DO ACESSO AO CONHECIMENTO TRADICIONAL ASSOCIADO E A REPARTIÇÃO DE BENEFÍCIOS DECORRENTES DE SUA EXPLORAÇÃO ECONÔMICA}

A Lei n. 13.123/2015 deu nova roupagem ao sistema de repartição de benefícios, em tentativa de regulamentação definitiva do tema e respeitando os acordos internacionais respectivos (TRIPs e $\mathrm{CDB})$.

Na sistemática da MP n. 2.186-16/2001 o Conselho de Gestão do Patrimônio Genético - CGen, órgão colegiado de caráter deliberativo, normativo, consultivo e recursal, era excessivamente centralizador e burocrático, pois todo o acesso ao patrimônio genético deveria obrigatoriamente ser antecedido de sua autorização prévia.

Pela nova lei, foi criado um modelo auto declaratório de cadastros e notificações, por meio do Sistema Nacional de Gestão do Patrimônio Genético e do Conhecimento Tradicional Associado - SisGen (MILARÉ; MORAIS, 2018) ${ }^{13}$, que poderá maior celeridade aos processos. 


\section{REFERÊNCIAS BIBLIOGRÁFICAS}

BOWMAN, Megan. Intellectual property rights, plant genetic resources and international law: potential conflicts and options for reconciliation. In: KIERKEGAARD, Sylvia Mercado. Business law \& technology: present and emerging trends. Dinamarca: Copenhagen, v. 1, 2006.

BRASIL. Lei n. 13.123 de 2015. Disponível em: < http://www.planalto.gov.br/ccivil_03/_Ato20152018/2015/Lei/L13123.htm\#art50>. Acesso em 9.ago.2017.

BRASIL. Decreto 8.772 de 2016. Disponível em: < http://www.planalto.gov.br/ccivil_03/_ato20152018/2016/decreto/D8772.htm>. Acesso em 9.ago.2017.

BRASIL. Ministério do Meio Ambiente. Disponível em <http://www.mma.gov.br/biodiversidade/biodiversidadebrasileira>. Acesso em 23.out.2018.

BRASIL. Ministério do Meio Ambiente. Convenção de Diversidade Biológica. Disponível em < http://www.mma.gov.br/informma/item/7513-conven\%C3\%A7\%C3\%A3o-sobre-diversidade-biol\%C3\%B3gica$c d b>$. Acesso em 24.out.2018.

BRASIL. Ministério do Meio Ambiente. Disponível em <http://www.mma.gov.br/informma/item/6141-paisesmegadiversos-discutem-reparticao-de-beneficios>. Acesso em 24.out.2018.

CONFERÊNCIA DAS NAÇÕES UNIDAS SOBRE MEIO AMBIENTE E DESENVOLVIMENTO. Convenção sobre Diversidade Biológica. Junho de 1992.

CONJUR, 23.jul.2008. Disponível em: <http://www.conjur.com.br/2008-jul23/empresa_alema_desiste_registro_marca_rapadura>. Acesso em: 9 ago. 2017.

DAVIES, Lorenice Freire. $\mathrm{O}$ sistema de patentes e a tutela dos conhecimentos tradicionais associados à biodiversidade. Dissertação de mestrado. Universidade Federal de Santa Maria/RS, 2015. Disponível em: < http://cascavel.ufsm.br/tede//tde_arquivos/50/TDE-2015-11-11T101428Z-

6741/Publico/DAVIES,\%20LORENICE\%20FREIRE.pdf>. Acesso em: 4.dez.2017.

DUTFIELD, Graham. Repartindo benefícios da biodiversidade: qual o papel do sistema de patentes?. In: PLATIAU, Ana Flávia Barros; VARELLA, Marcelo Dias (Org.). Diversidade biológica e conhecimentos tradicionais. Belo Horizonte: Del Rey, 2004.

FILIPPIN, Rafael Ferreira; IACOMINI, Vanessa; HALICKI, Zélia; VENERAL, Débora Cristina. Coleção Direito Processual Civil e Direito Ambiental: Inovações do direito ambiental, biodireito e biodiversidade, e economia e meio ambiente. Curitiba: Intersaberes, 2014.

FINGER, J. Michael. Poor people's knowledge: helping poor people to earn from their knowledge. Disponível em: $<$ http://www-

wds.worldbank.org/servlet/WDSContentServer/WDSP/IB/2004/04/15/000009486_20040415114839/Rendered /PDF/wps3205poorpeople.pdf>. Acesso em: 15 fev. 2007. 
O CGEN, entretanto, continua a ser o responsável por coordenar a elaboração e a implementação de políticas para a gestão do acesso ao patrimônio genético e ao conhecimento tradicional associado e da repartição de benefícios, formado por representação de órgãos e entidades

MACHADO, Carlos José Saldanha e GODINHO, Rosemary de Sampaio. Dinâmica e caraterísticas do processo brasileiro de regulação do acesso à diversidade biológica e aos conhecimentos tradicionais associados. Revista de Informação Legislativa. Brasília a 48, n. 191, jul/set. 2011, p. 99/121. Disponível em <http://www2.senado.leg.br/bdsf/bitstream/handle/id/242911/000926854.pdf>. Acesso em 23.out.2018.

MAGALHÃES, Vladimir Garcia. Propriedade intelectual: biotecnologia e biodiversidade. São Paulo: Editora Fiuza, 2011.

MENDONÇA, Guilherme Cruz de. Interfaces entre a proteção da cultura quilombola e a conservação da biodiversidade. In: BENJAMIM, Antônio Herman (Org.). Direitos humanos e meio ambiente. São Paulo: Imprensa Oficial do Estado de São Paulo, 2006.

MILARÉ, Édis e MORAIS, Roberta Jardim de. Questões sobre o prazo de adequação estabelecido pela lei de biodiversidade. CONJUR. Disponível em: < https://www.conjur.com.br/2018-ago-29/opiniao-prazo-adequacaolei-biodiversidade>. Acesso em: 29.out.2018.

MOREIRA, Eliane Cristina Pinto; CONDE, Leandro Barbalho. A Lei n. 13.123/2015 e o Retrocesso na Proteção dos Conhecimentos Tradicionais. Veredas do Direito, Belo Horizonte, v. 14, n. 29, p. 175-205, mai./ago. 2017. Disponível em: Acesso em: 21.fev.2019.

PARÁ. OAB/PA. Disponível em: <http://www.oab.pa.org.br>. Acesso em: 10 abr. 2007.

ROHRMANN, Carlos Alberto. Curso de direito virtual. Belo Horizonte: Del Rey, 2005.

ROHRMANN, Carlos Alberto; SIQUEIRA, Lyssandro Norton. Intellectual property rights, plant genetic resources and international law: potential conflicts and options for reconciliation. In: KIERKEGAARD, Sylvia Mercado. Business law \& technology: present and emerging trends. Dinamarca: Copenhagen, v. 1, 2006.

SAINT-HILAIRE, A. de. Viagem pelo Distrito dos Diamantes e litoral do Brasil. Belo Horizonte: Itatiaia; São Paulo: Universidade de São Paulo, 1974.

SANTILLI, Juliana. Biodiversidade e conhecimentos tradicionais associados: novos avanços e impasses na criação de regimes legais de proteção. Revista de Direito Ambiental. São Paulo: Revista dos Tribunais, n. 29, p. 83-102, jan./mar. 2003.

SANTILLI, Juliana. Conhecimentos tradicionais associados à biodiversidade: elementos para a construção de um regime jurídico sui generis de proteção. In: PLATIAU, Ana Flávia Barros; VARELLA, Marcelo Dias (org.). Diversidade biológica e conhecimentos tradicionais. Belo Horizonte: Del Rey, 2004.

VISENTIN, Maria Alice Dias Rolim. Acesso a recursos genéticos, repartição de benefícios e propriedade intelectual: A conservação da biodiversidade e os direitos de patentes. Veredas do Direito: Direito Ambiental e Desenvolvimento Sustentável, Belo Horizonte, v. 9, n. 17, p. 163, dez. 2012. ISSN 21798699. Disponível em: <http://www.domhelder.edu.br/revista/index.php/veredas/article/view/229/213>. Acesso em: 04 Dez. 2017.

Revista de Direito da Cidade, vol. 11, no 2. ISSN 2317-7721 pp. 439-456 452 
da administração pública federal que detêm competência sobre as diversas ações de que trata a lei com participação máxima de 60\% (sessenta por cento) e a representação da sociedade civil em no mínimo 40\% (quarenta por cento) dos membros, assegurada a paridade entre setor empresarial, setor acadêmico, e populações indígenas, comunidades tradicionais e agricultores tradicionais.

A lei garante direitos às populações indígenas, às comunidades tradicionais e aos agricultores tradicionais que criam, desenvolvem, detêm ou conservam conhecimento tradicional associado, como os de terem reconhecida sua contribuição para o desenvolvimento e conservação de patrimônio genético, em qualquer forma de publicação, utilização, exploração e divulgação e participarem do processo de tomada de decisão sobre assuntos relacionados ao acesso a conhecimento tradicional associado e à repartição de benefícios decorrente desse acesso.

Nos termos do art. 9o, o acesso a conhecimento tradicional associado de origem não identificável independe de consentimento prévio informado. Neste ponto, a lei, para Eliane Cristina Pinto Moreira e Leandro Barbalho Conde, promoveu retrocesso na proteção dos conhecimentos tradicionais:

Nesse aspecto, o novo marco legal, a fim de identificar os saberes tradicionais associados até então de origem não identificável, deveria ter criado, no mínimo, instrumentos que condicionassem o acesso à consulta sobre esses conhecimentos, por exemplo, no Livro de Registro dos Saberes, acima comentado. Caso não constasse o registro desse saber nesse Livro, a lei deveria vincular o acesso ao registro, para que uma próxima atividade de acesso estivesse sujeita ao consentimento da população tradicional provedora desse conhecimento antes sem origem identificável (MOREIRA; CONDE, 2017, p. 187).

Já o acesso ao conhecimento tradicional associado de origem identificável está condicionado à obtenção do consentimento prévio informado, que poderá ocorrer, a critério da população indígena, da comunidade tradicional ou do agricultor tradicional, pelos seguintes instrumentos: assinatura de termo de consentimento prévio; registro audiovisual do consentimento; parecer do órgão oficial competente; ou adesão na forma prevista em protocolo comunitário.

O Decreto n. 8.772/2016, em seu art. 16, determina que o interessado deverá observar as seguintes diretrizes para a obtenção do consentimento prévio informado: esclarecimentos à população indígena, comunidade tradicional ou agricultor tradicional sobre: a) os impactos sociais, culturais e ambientais decorrentes da execução da atividade envolvendo acesso ao conhecimento tradicional associado; b) os direitos e as responsabilidades de cada uma das partes na execução da atividade e em seus resultados; e c) o direito da população indígena, comunidade tradicional e agricultor tradicional de recusar o acesso ao conhecimento tradicional associado; estabelecimento, em conjunto com a população indígena, comunidade tradicional ou agricultor tradicional, das modalidades de repartição 
de benefícios, monetária ou não monetária, derivadas da exploração econômica; e respeito ao direito da população indígena, comunidade tradicional e agricultor tradicional de recusar o acesso ao conhecimento tradicional associado, durante o processo de consentimento prévio.

Nos termos do disposto no art. 17, os benefícios resultantes da exploração econômica de produto acabado ou de material reprodutivo oriundo de acesso ao patrimônio genético de espécies encontradas em condições in situ ou ao conhecimento tradicional associado, ainda que produzido fora do País, serão repartidos, de forma justa e equitativa, sendo que no caso do produto acabado o componente do patrimônio genético ou do conhecimento tradicional associado deve ser um dos elementos principais de agregação de valor, estando sujeito à repartição de benefícios exclusivamente o fabricante do produto acabado ou o produtor do material reprodutivo, independentemente de quem tenha realizado o acesso anteriormente.

A repartição de benefícios poderá ser monetária ou não monetária, incluindo, entre outras: projetos para conservação ou uso sustentável de biodiversidade ou para proteção e manutenção de conhecimentos, inovações ou práticas de populações indígenas, de comunidades tradicionais ou de agricultores tradicionais, preferencialmente no local de ocorrência da espécie em condição in situ ou de obtenção da amostra quando não se puder especificar o local original; transferência de tecnologias; disponibilização em domínio público de produto, sem proteção por direito de propriedade intelectual ou restrição tecnológica; licenciamento de produtos livre de ônus; capacitação de recursos humanos em temas relacionados à conservação e uso sustentável do patrimônio genético ou do conhecimento tradicional associado; e distribuição gratuita de produtos em programas de interesse social.

Quando a modalidade escolhida for a repartição de benefícios monetária, será devida, nos termos do art. 20, uma parcela de $1 \%$ (um por cento) da receita líquida anual obtida com a exploração econômica.

O art. 21 prevê que a União poderá, a pedido do interessado, celebrar acordo setorial que permita reduzir o valor da repartição de benefícios monetária para até $0,1 \%$ (um décimo por cento) da receita líquida anual obtida com a exploração econômica do produto acabado ou do material reprodutivo oriundo de acesso ao patrimônio genético ou ao conhecimento tradicional associado de origem não identificável.

Quando o produto acabado ou o material reprodutivo for oriundo de acesso ao conhecimento tradicional associado que seja de origem identificável, o provedor de conhecimento tradicional associado terá direito de receber benefícios mediante acordo de repartição de benefícios, que será negociado de forma justa e equitativa entre as partes, atendendo a parâmetros de clareza, lealdade e transparência nas cláusulas pactuadas, que deverão indicar condições, obrigações, tipos e duração dos benefícios de curto, médio e longo prazo. 
Buscando a conciliação entre o TRIPs e a CDB, a lei prevê em seu art. 47 que a concessão de direito de propriedade intelectual pelo órgão competente sobre produto acabado ou sobre material reprodutivo obtido a partir de acesso a patrimônio genético ou a conhecimento tradicional associado fica condicionada ao cadastramento ou autorização.

\section{CONCLUSÃO}

A CDB, um dos instrumentos internacionais mais importantes relacionados ao meio ambiente, constitui marco normativo para a conservação da diversidade biológica, a utilização sustentável de seus componentes e a repartição justa e equitativa dos benefícios derivados da utilização do patrimônio genético.

Quanto à repartição dos benefícios resultando do acesso ao conhecimento tradicional associado ao patrimônio genético, a aplicação da CDB, no plano internacional, tem conflitos pontuais com a aplicação do TRIPs.

A solução, definitiva para esse conflito, está relacionada à construção de um sistema normativo internacional melhor adequado às especificidades dos conhecimentos tradicionais e de seus detentores, consagrando, como exigência à concessão de patentes, a identificação da fonte do conhecimento tradicional utilizado e a prova da obtenção do consentimento prévio e fundamentado e da repartição justa e equitativa de benefícios.

Atualmente, em face da ausência de tal regulação internacional definitiva, deve-se aplicar ao tema os institutos jurídicos já existentes. Cumpre aos países detentores de biodiversidade o fortalecimento dos órgãos destinados à pesquisa e identificação dos conhecimentos tradicionais associados e das comunidades que o desenvolveram. O fortalecimento desta base de dados permitiria, ainda que precariamente, a oposição aos pedidos de patentes, com fulcro na ausência do requisito da novidade, protegendo-se, assim, as comunidades indígenas ou tradicionais, ainda que precariamente.

No Brasil, o país mais rico do mundo em biodiversidade, a primeira normatização da questão, por meio da MP n. 2.186-16/2001, teve o mérito de regulamentar o tema, mas seu conteúdo gerou diversas controvérsias e discussões conceituais que acabaram dificultando a garantia dos direitos dos detentores de conhecimentos tradicionais associados que são usados pelas comunidades científicas e pelos empreendedores do setor.

A edição da Lei n. 13.123/2015, regulamentada pelo Decreto n. 8.772/2016, se revela como boa contribuição para a tentativa de solução das controvérsias jurídicas no Brasil, ao regulamentar de modo detalhado a repartição de benefícios decorrente do acesso ao conhecimento tradicional associado à biodiversidade trazendo segurança jurídica para o setor produtivo e instrumentos de proteção para as comunidades tradicionais, titulares do conhecimento tradicional associado à biodiversidade. 
NOTAS

Trabalho enviado em 12 de novembro de 2018 Aceito em 04 de fevereiro de 2019 